\title{
How can the work of junior paediatricians be reduced?
}

\author{
C. M McKee, P Priest, M Ginzler, N A Black
}

In 1989 the British Postgraduate Medical Federation (BPMF) issued a report which voiced concern about the pattern of junior staffing in paediatrics. ${ }^{1}$ The report, which was based on a survey in five districts, found that junior staff in paediatrics work for longer hours than in other specialities, are the busiest doctors in a hospital at night, and are the most likely to have an interrupted night while on duty. The BPMF report, and a subsequent agreement by the ministerial group on junior doctors' hours, ${ }^{2}$ have called for research as to how the volume of work can be reduced and, in particular, whether some tasks might either be postponed until morning or delegated to other professionals. We report the results of such a study.

\section{Methods}

The study was performed in two phases. In the first phase the tasks undertaken by junior doctors in four NHS hospitals were identified. These included one teaching hospital and three district general hospitals, in inner and outer London and in a rural district about 50 miles from London. Paediatric junior staff used diaries, designed after a pilot study in one of the hospitals, to record alf activities undertaken between $5 \mathrm{pm}$ and 9am over a seven day period. Diaries were completed by eight senior house officers, two registrars, and a senior registrar. The information recorded included whether the activity was self initiated or as a result of a request from other staff, the time of commencement, details of the request, and the activity undertaken. The doctors described the activities in their own words. These data were supplemented by interviews with five senior house officers and a registrar and by comments from a meeting attended by all grades of medical staff and nurses in a paediatric department in one of the hospitals concerned. A report was compiled using information collected during this phase, supplemented with a review of relevant literature.

In the second phase, a panel of relevant professionals was established. It was composed of: six consultant paediatricians, two consultant obstetricians, and a paediatric senior house officer. The consultants were selected from hospitals throughout the region.

A nominal group technique described by Glaser was employed. ${ }^{3}$ Approximately six weeks before the date of the panel meeting each participant was sent (i) the report which had been produced in the first phase of the study, (ii) a review of current concerns about the work of junior doctors and arguments for and against the existing system, and (iii) a first round questionnaire which sought panellists' views as to the appropriateness of a paediatrician performing certain tasks at night.

Appropriateness was scored on a nine point scale, with 1 meaning the task was totally inappropriate for a non-medical member of staff and 9 meaning it would always be appropriate for a non-medical member of staff to perform the task. The responses to the questionnaire were collated and at the panel meeting each participant was provided with a new copy of the questionnaire in which the group responses were indicated. The meeting was chaired by one of us (NAB) and lasted about three hours. Participants were given lunch and reimbursed for travelling expenses, but there was no other payment. After an introductory explanation, each item on the questionnaire about which there were a variety of opinions was discussed. At the end of the discussion on each question panellists were again asked to score the task on a scale from 1 to 9 . There was no pressure on panellists to reach consensus.

The responses were analysed for agreement or disagreement and a record of the discussion was transcribed. Agreement was deemed to be present when, after discarding the single highest and lowest scores, the remaining scores of all nine panellists lay within a three point range. Disagreement occurred when, after discarding the single highest and lowest scores, at least one of the remaining seven scores was 1-3 and at least one was 7-9. All other results were designated as partial agreement. The rationale for this scoring system has been described elsewhere. ${ }^{4}$

\section{Results}

QUANTITATIVE DESCRIPTION OF TASKS

It was not possible to distinguish with certainty between activities relating to general and those relating to neonatal paediatrics. This was mainly because of the organisation of the service. In hospital $\mathrm{C}$ both are covered by a single senior house officer although the facilities are on sites which are several miles apart, whereas in hospitals A, B, and D, separate senior house officers cover general and neonatal paediatrics. They are also on separate sites in districts B and D. In all cases a single registrar covers both components when on duty, although in district 
B that individual also covers hospitals in neighbouring districts.

Clinical tasks, such as admitting and reviewing children, resuscitating infants, and prescribing, constituted $44 \%$ of recorded activities (table 1). The next most frequent category, comprising $19 \%$ of activities, consisted of a series of technical tasks of varying complexity. This was followed by giving and receiving advice. As expected, this was a major component of the work of registrars. Finally clerical tasks and attendance at deliveries each comprised approximately a tenth of recorded activities.

\section{INTERHOSPITAL COMPARISONS}

The small number of respondents precluded quantitative comparison between hospitals. However, qualitative differences in policy on the requirement for a paediatrician to be present at a delivery and the division of tasks between doctors and nurses were obtained (tables 2 and 3).

\section{ATTITUDES OF JUNIOR STAFF}

Paediatric junior staff demonstrated considerable dissatisfaction largely because of the intensity of work. Some specific issues were raised involving work which was seen to be unnecessary. The principal issue involved attendance at deliveries. They saw their role at most deliveries as precautionary, which was largely inevitable because of the difficulty in predicting which infants would require their assistance. However, several questioned whether a paediatrician should routinely be called to certain types of delivery. Conversely some senior house officers recalled situations where they had not

Table 1 Analysis of activities from diaries completed by junior doctors (column percentages in parentheses)

\begin{tabular}{|c|c|c|c|c|}
\hline & $\begin{array}{l}\text { Senior house } \\
\text { officer }\end{array}$ & Registrar & $\begin{array}{l}\text { Senior } \\
\text { registrar }\end{array}$ & All \\
\hline $\begin{array}{l}\text { No of diaries } \\
\text { (1) Clinical tasks: } \\
\text { Resuscitate child } \\
\text { Review patient in ward } \\
\text { See patient in accident and emergency } \\
\text { Admit to SCBU/NNU } \\
\text { Clerk patient } \\
\text { Prescribe drugs } \\
\text { Prescribe intravenous fluids } \\
\text { Order } x \text { ray films } \\
\text { Monitor baby awaiting transfer } \\
\text { Subtotal }\end{array}$ & $\begin{aligned} 8 \\
\\
16(7) \\
25(11) \\
29(13) \\
7(3) \\
12(6) \\
6(3) \\
3(1) \\
3(1) \\
101(46)\end{aligned}$ & $\begin{array}{l}2 \\
2(5) \\
10(23) \\
3(7)\end{array}$ & $\begin{array}{l}1 \\
2(13) \\
2(13) \\
1(6)\end{array}$ & $\begin{aligned} 11 \\
20(7) \\
37(13) \\
29(10) \\
11(4) \\
12(4) \\
6(2) \\
3(1) \\
3(1) \\
1(0) \\
122(44)\end{aligned}$ \\
\hline $\begin{array}{l}\text { (2) Technical tasks: } \\
\text { Blood sample } \\
\text { Arterial } \\
\text { Venous } \\
\text { Re/site intravenous infusion } \\
\text { Give intravenous drugs } \\
\text { Septic screen } \\
\text { Analyse blood for bilirubin } \\
\text { Insert chest drain } \\
\text { Lumbar puncture } \\
\text { Add drugs to infusion } \\
\text { Exchange transfusion (neonate) } \\
\text { Insert nasogastric tube } \\
\text { Subtotal }\end{array}$ & $\begin{aligned} & 12(6) \\
& 9(4) \\
& 8(4) \\
& 4(2) \\
& 2(1) \\
& 4(2) \\
& 1(0) \\
& 1(0) \\
& 1(0) \\
& 42(19)\end{aligned}$ & $\begin{array}{l}2(5) \\
3(7) \\
2(5) \\
1(2) \\
2(5) \\
1(2) \\
11(25)\end{array}$ & $1(6)$ & $\begin{aligned} & 14(5) \\
& 12(4) \\
& 11(4) \\
& 4(1) \\
& 3(1) \\
& 4(1) \\
& 2(1) \\
& 11(0) \\
& 11(0) \\
& 11(0) \\
& 1(0) \\
& 54(19)\end{aligned}$ \\
\hline $\begin{array}{l}\text { (3) Advice: } \\
\text { Consult with other doctor } \\
\text { Talk to relatives } \\
\text { Advise nurses by phone } \\
\text { Advise general practitioner by phone } \\
\text { Reassure patient } \\
\text { Subtotal }\end{array}$ & $\begin{aligned} 19(9) \\
4(2) \\
2(1) \\
1(0) \\
1(0) \\
27(12)\end{aligned}$ & $\begin{array}{l}9(20) \\
3(7) \\
1(2) \\
13(30)\end{array}$ & $6(38)$ & $\begin{aligned} 34 & (12) \\
7 & (3) \\
3 & (1) \\
1 & (0) \\
1 & (0) \\
46 & (17)\end{aligned}$ \\
\hline $\begin{array}{l}\text { (4) Administrative clerical tasks: } \\
\text { Complete accident form } \\
\text { Dictate discharge summaries } \\
\text { File results } \\
\text { Liaise with other agency } \\
\text { Organise beds } \\
\text { Organise blood transfusion } \\
\text { Pursue results } \\
\text { Teaching } \\
\text { Subtotal }\end{array}$ & $\begin{array}{r}1(0) \\
2(1) \\
1(0) \\
8(4) \\
3(1) \\
3(1) \\
1(0) \\
1(0) \\
20(9)\end{array}$ & & $\begin{array}{ll} & \\
1 & (6) \\
1 & (6) \\
3 & (19)\end{array}$ & $\begin{array}{c}1(0) \\
3(1) \\
1(0) \\
8(3) \\
3(1) \\
3(1) \\
2(1) \\
2(1) \\
23(8)\end{array}$ \\
\hline (5) Attend delivery & $28(13)$ & $4(9)$ & $1(6)$ & $33(12)$ \\
\hline Total & $218(100)$ & $44(100)$ & $16(100)$ & $278(100)$ \\
\hline
\end{tabular}

SCBU/NNU, special care baby unit/neonatal unit.

Table 2 Variations in practice between four hospitals $(A, B, C$, and $D)$ regarding tasks undertaken by junior doctors

\begin{tabular}{lllll}
\hline Task & $A$ & $B$ & $C$ & $D$ \\
\hline Give intravenous drugs & First dose & Yes & First dose & only \\
Add additives to infusions & No & Yes & No & Midnight \\
Supervise blood transfusions & No & Yes & No & No \\
Take blood samples & No & Yes & No & No \\
Yes
\end{tabular}

Source: interviews with junior doctors. 
Table 3 Circumstances in which a paediatrician is present at birth between four hospitals $(A, B, C$, and $D)$

\begin{tabular}{|c|c|c|c|c|}
\hline Task & $A$ & $B$ & $C$ & $D$ \\
\hline Forceps delivery & $\begin{array}{l}\text { Yes } \\
\quad \text { (including lift out forceps) }\end{array}$ & Yes & Yes & Yes \\
\hline Intrapartum fetal distress & Yes & Yes & Yes & Yes \\
\hline Caesarean section & Yes & Yes & Yes & Yes \\
\hline Meconium staining & Yes & Yes & Yes & Yes \\
\hline Severe growth retardation & $\begin{array}{l}\text { Usually (often called } \\
\text { after birth) }\end{array}$ & Yes & Yes & $\begin{array}{l}\text { Usually (often } \\
\text { called after birth) }\end{array}$ \\
\hline Maternal diabetes & Yes & Yes & Yes & No \\
\hline Rhesus incompatibility & Yes & Yes & Yes & Called after birth \\
\hline Fetal abnormalities & Called after birth & Sometimes & Yes & Yes \\
\hline Multiple births & Yes & Yes & Yes & Yes \\
\hline Profuse vaginal bleeding & Yes & No & No & No \\
\hline Abnormal presentation & Yes & Yes & Yes & Yes \\
\hline
\end{tabular}

Source: interviews with junior doctors.

been called because a member of the delivery team was sufficiently confident at resuscitation. In particular, some midwives were much more willing to resuscitate babies than others, and a few instances were recalled when midwives had undertaken intubation. On other occasions a paediatrician was not called because the obstetric senior house officer had neonatal experience. This was especially relevant in the one hospital, where doctors perform a higher proportion of normal deliveries than in other hospitals, although in another, where virtually all normal deliveries are carried out by midwives, one paediatrician expressed slight annoyance about being called to many deliveries when the obstetric senior house officer was not.

There was also irritation about being called long before a delivery occurs. They accepted that the duration of labour is often unpredictable, but paediatricians were often called to caesarean sections at the same time as anaesthetists, with a lengthy delay before the baby is born. This leads to postponement of other work.

They drew attention to the complexity of treating neonates. This was substantiated by several episodes recorded in diaries where a single child occupied a senior house officer for up to six hours. Support from registrars was a problem where neonatal units and general paediatric wards were on separate sites. Especially in urban hospitals there was concern that poor quality primary care contributed considerably to paediatric workload, through inappropriate referrals and telephone calls from parents who were unable to contact their general practitioner.
There were also a number of specific problems in individual units. For example, in one hospital, adult patients with thalassaemia or sickle cell disease continue to be treated by paediatric junior staff, undergoing check ups and transfusions in the evenings to fit in with their employment. It may take up to an hour to treat each patient, at a time when doctors are particularly busy with calls from accident and emergency departments. In another, a blood gas analyser was provided but without technical support. On occasions senior house officers spent up to two hours repairing it.

\section{CONSENSUS PANEI}

Two broad areas of concern emerged from the first phase attendance at deliveries and certain technical tasks. Tasks that clearly require a doctor (clerking and examining patients, prescribing drugs, talking to relatives and senior colleagues) were not considered by the panel and administrative and clerical tasks had been considered by another panel (to be reported elsewhere). This left two areas for discussion: technical tasks and attendance at deliveries.

\section{TECHNICAL TASKS}

Following discussion, the panel considered many of these tasks need not be performed by a doctor (table 4). Some panellists were initially reluctant to accept this view but agreed that nurses could take on such roles if they were properly trained. It was, however, pointed out by other panellists that many paediatric senior house officers receive no formal training in taking blood samples and

Table 4 Appropriateness of tasks being performed by someone other than a doctor

\begin{tabular}{lll}
\hline Task & $\begin{array}{l}\text { Level of } \\
\text { agreement }\end{array}$ & $\begin{array}{l}\text { Median } \\
\text { score* }\end{array}$ \\
\hline $\begin{array}{l}\text { Must be done by doctor: } \\
\text { Take arterial blood from child, no arterial line in situ }\end{array}$ & Agreement \\
Need not be done by doctor: & & \\
Site an intravenous cannula in a child & Agreement \\
Site an intravenous cannula in a neonate & $\begin{array}{l}\text { Partial agreement } \\
\text { Draw/make up intravenous drugs }\end{array}$ & 9 \\
Administer intravenous drugs & $\begin{array}{l}\text { Agreement } \\
\text { Take venous blood from a child }\end{array}$ & 9 \\
Take venous blood from a neonate & $\begin{array}{l}\text { Agreement } \\
\text { Partial agreement }\end{array}$ & 8 \\
Take arterial blood from child or neonate with arterial line in situ & $\begin{array}{l}\text { Agreement } \\
\text { Agreement } \\
\text { Analyse blood samples in neonatal unit }\end{array}$ & 9 \\
Agreement & 9 \\
Disagreement: & & 9 \\
Take arterial blood from neonate, no arterial line in situ & Disagreement \\
Intubate a neonate after delivery & Disagreement & 9 \\
\hline
\end{tabular}

${ }^{*}$ Score: 1 , must be done by a doctor, 9 , can always be done by someone else. 
inserting cannulae in children. One panellist contrasted this with a Canadian unit in which nurses are responsible for all intravenous infusions. It was also noted that when doctors are required to give intravenous drugs, other tasks such as attending deliveries take precedence and the drugs are often given several hours late. This would be avoided if they were given by nurses on drug rounds.

Panellists challenged the practice in some units for doctors to give the first dose of all routine intravenous drugs because of the possible risk of anaphylaxis. It was felt to be unnecessary as a reaction could occur at any stage in a course of treatment.

The inclusion of heel stabs in the discussion aroused surprise among those panellists working in units where it is a routine nursing task, although others reported that it is always done by doctors in their units.

The disagreement about intubating neonates partially reflected an ambiguity in the question. It may be required in two situations: as an emergency after delivery if a paediatrician is not present and if a tube becomes dislodged in a neonatal unit. In the first case it was argued that midwives should be able to intubate, although there was concern that they might lose their skills if they were not doing it routinely. Others argued that resuscitation with a bag and mask was often adequate until a paediatrician arrives.

Arterial stabs in neonates also produced disagreement. While some panellists took the view that nurses could perform the task satisfactorily, others disagreed because of the perceived risk of arterial spasm. However, it was argued that a nurse could manage this as well as a doctor. One panellist expressed caution that a policy whereby nurses could take samples only from arterial lines may lead to their more widespread use.

\section{ATTENDANCE AT DELIVERIES}

The panel's views on the need for a paediatrician to attend deliveries in particular circumstances are shown in table 5 . The reasoning behind these views will be discussed for each situation in turn.
(1) PREGNANCIES 'AT RISK' FROM THE ANTENATAL HISTORY

\section{Maternal diabetes}

The question was restricted to an otherwise uncomplicated labour. Several arguments were advanced for a paediatrician being present, including the high incidence of unexpected congenital abnormalities, and the need for an additional pair of hands as the midwives and obstetricians may be involved with problems affecting the mother. The need for careful preparation was stressed, and several commented that they should be planned to match laboratory working hours. The lack of complete agreement partially reflected a dichotomy in which those working in London felt that a paediatrician should be present, whereas those outside London felt that it was only that the infant should be seen within one hour. Presence at such deliveries may have a lower priority than some other tasks.

\section{Rhesus incompatibility}

A paediatrician should be present if the baby is premature and anaemic but not if there has only been a rise in antibody during pregnancy. However, each case should be discussed between the obstetricians and paediatricians in advance.

\section{Pre-eclampsia}

These pregnancies will be monitored closely by obstetricians. The panel agreed that a paediatrician need only be present if the fetal heart trace was unsatisfactory or the baby has not been growing well.

\section{Known congenital abnormality}

This topic generated considerable debate. Many mild abnormalities would not require a paediatrician, although prenatal diagnosis is often uncertain and unforeseen problems may arise. Even when a paediatrician is not required at the delivery, the infant should be seen soon after. The paediatrician has a dual function in deliveries of infants with major abnormalities: resuscitating the infant and counselling parents. Such deliveries should be planned, and when

Table 5 Indications for a paediatrician to be present at a delivery

\begin{tabular}{|c|c|c|c|}
\hline Indication & Level of agreement & Median score* & $\begin{array}{l}\text { Need for } \\
\text { paediatrician }\end{array}$ \\
\hline $\begin{array}{l}\text { (1) Pregnancies at risk from the antenatal history: } \\
\text { Maternal diabetes } \\
\text { Rhesus incompatibility } \\
\text { Pre-eclampsia } \\
\text { Known congenital abnormality } \\
\text { Multiple births }\end{array}$ & $\begin{array}{l}\text { Partial agreement } \\
\text { Agreement } \\
\text { Agreement } \\
\text { Partial agreement } \\
\text { Agreement }\end{array}$ & $\begin{array}{l}2 \\
5 \\
5 \\
3 \\
1\end{array}$ & $\begin{array}{l}\text { Sometimes } \\
\text { Sometimes } \\
\text { Sometimes } \\
\text { Sometimes } \\
\text { Yes }\end{array}$ \\
\hline $\begin{array}{l}\text { (2) Preterm births (weeks' gestation): } \\
34-36 \\
30-34 \\
<30\end{array}$ & $\begin{array}{l}\text { Agreement } \\
\text { Agreement } \\
\text { Agreement }\end{array}$ & $\begin{array}{l}5 \\
1 \\
1\end{array}$ & $\begin{array}{l}\text { Sometimes } \\
\text { Yes } \\
\text { Yes }\end{array}$ \\
\hline $\begin{array}{l}\text { (3) Difficulties during labour: } \\
\text { Abnormal presentation } \\
\text { Suspected birth asphyxia } \\
\text { Meconium staining }\end{array}$ & $\begin{array}{l}\text { Agreement } \\
\text { Agreement } \\
\text { Agreement }\end{array}$ & $\begin{array}{l}1 \\
1 \\
4\end{array}$ & $\begin{array}{l}\text { Yes } \\
\text { Yes } \\
\text { Sometimes }\end{array}$ \\
\hline $\begin{array}{l}\text { (4) Instrumental deliveries: } \\
\text { Lift out forceps } \\
\text { Difficult forceps } \\
\text { Emergency caesarean section }\end{array}$ & $\begin{array}{l}\text { Partial agreement } \\
\text { Agreement } \\
\text { Agreement }\end{array}$ & $\begin{array}{l}6 \\
1 \\
1\end{array}$ & $\begin{array}{l}\text { Sometimes } \\
\text { Yes } \\
\text { Yes }\end{array}$ \\
\hline
\end{tabular}

${ }^{*}$ Score: 1 , paediatrician must be present, 9 , paediatrician need never be present. 
appropriate, should take place in hospitals with a paediatric surgical unit. It is preferable for a consultant to counsel the parents, and this is likely to be unsatisfactory if done in the middle of the night. The final rating reflected the lack of specificity in the question. The topic requires more detailed consideration, and cases should be discussed individually between a paediatrician and an obstetrician.

\section{(2) PRETERM BIRTHS}

It.was noted that junior staff in many hospitals are called to all preterm births. However, it was agreed that infants of 34 weeks' gestation or more rarely have problems, and as they are intensively monitored the need for a paediatrician can usually be predicted.

\section{(3) DIFFICULTIES DURING LABOUR}

A paediatrician should always be present in cases of abnormal presentation and where asphyxia is suspected from the fetal heart trace or fetal blood monitoring. It is especially important in the latter case because of the medicolegal implications. There was much more debate about the importance of meconium staining, with differing views about the correlation with asphyxia. It was noted to be a common reason for being called to a delivery, but many babies required no treatment.

\section{(4) INSTRUMENTAL DELIVERIES}

A paediatrician should be present for difficult forceps deliveries and caesarean sections, but there is less certainty about 'lift out' forceps deliveries. One panellist cited a hospital in which only one of two obstetric teams routinely called a paediatrician.

\section{Discussion}

During the past 30 years there have been major increases in the workload of paediatricians. General paediatrics has been affected by the steady increase in attendances at accident and emergency departments, and the ability to treat babies of ever decreasing gestation has increased the scale of neonatal care dramatically. ${ }^{5}$ This has affected both the number of infants treated, and also the complexity and intensity of treatment. However, changes in the work pattern of doctors have not kept pace with these changes, with the result that paediatrics is generally recognised to be the busiest speciality in a typical hospital.

This panel has provided a basis for discussions on ways to reduce this workload. Responsibility for many technical tasks could be adopted by other professionals. This may be less of a problem in paediatrics than elsewhere as, especially in neonatal units, many nurses have undergone advanced training. Attendance at deliveries could also be reduced. Although most of the factors considered by the panel are regarded as indications to call a paediatrician in each of the study hospitals, it was apparent that many junior paediatricians questioned these policies. Many of their reservations are borne out by the panel. The view that a paediatrician need not be present at all at lift out forceps deliveries is consistent with the findings of one of the few studies in this area which found no difference in the proportion of infants requiring resuscitation in spontaneous vaginal deliveries compared with those where Neville-Barnes forceps were used. ${ }^{6}$ There is a particular need for improved communication in advance between obstetricians and paediatricians, but the panel has drawn attention to areas requiring more research in neonatal practice, such as the poor predictive value of current methods of intrapartum monitoring and uncertainty about the importance of meconium staining. ${ }^{7}$ Also the role of a paediatrician at the delivery of an infant with a known congenital abnormality, and the skills which are required, need further consideration.

Applying the panel's conclusions to the activities recorded by senior house officers in the diaries, and with certain assumptions, our best estimate is that approximately $25 \%$ of the events recorded in diaries could be avoided. This increases to $40 \%$ if activities after midnight are considered separately. Such a reduction would not resolve all of the problems of junior paediatricians, and many would still have an arduous job. The importance of implementing such measures was stressed by some of the panellists who commented on the difficulty of recruiting junior staff. Paediatricians up to senior registrar grade often work for most of the night when on call. The implications of the panel's conclusions resemble those proposed in response to a similar problem in Canada where there was understaffing in many units and reluctance to enter the speciality resulting from the heavy workload and long hours of work. ${ }^{8}$ The heavy clinical load was also felt to compromise the educational objectives of paediatric training posts. The authors argued that the problem required not only an increase in neonatologists, but also a consideration of whether some of the tasks undertaken by neonatologists could be performed by other professionals. This paper is a contribution to that debate.

This work received financial support from the Department of Health. We are grateful to the participants in the panel: Dr T W P Bate, Dr J Bunn, Dr G Cheriyan, Dr J Evans Jones, Dr A J Franklin, Dr R J Harris, Mr M A Pugh, and Dr M O Savage. We also thank the medical and nursing staff of the hospitals We also thank the medical and nursing staff of the hospital
concerned. The views expressed are those of the authors alone.

1 Dowie R. Patterns of medical staffing. Interim report. London: British Postgraduate Medical Federation, 1989.

2 Ministerial group on junior doctors' hours. Funior doctors' hours. London: United Kingdom Departments of Health, 1900.

3 Glaser EM. Using behavioural science strategies for defining the state-of-the-art. Fournal of Applied Behavioural Science 1980;16:79-92.

4 Scott EA, Black NA. When does consensus exist in exper panels? F Public Health Med 1991;13:35-9.

5 Hack M, Fanaroff AA, Merkatz IR. The low birth weigh infant-evolution of a changing outlook. $N$ Engl f Med 1979;301:1162-5.

6 Gray LC, Grant HW. Should a paediatrician be present at non-rotational forceps deliveries? Br $\mathcal{F}$ Obstet Gynaecol 1984;91:899-900.

7 Steer PJ, Eigbe F, Lissauer TJ, Beard RW. Interrelationships among abnormal cardiotocograms in labor, meconium staining of the amniotic fluid, arterial cord blood mH, and Apgar scores. Obstet Gynecol 1989;74:715-21.

$8 \mathrm{Paes}$ B, Mitchell A, Hun berger M, et al. Medical staffing in Ontario neonatal intensive care units. Can Med Assoc $\mathcal{J}$ 1989;140:1321-6. 